\title{
Expression of TGF- $\beta 1$ and miRNA-145 in patients with diabetic foot ulcers
}

\author{
FENGMEI ZHANG ${ }^{1}$, YUGUO REN $^{2}$, PENG LIU $^{1}$, YUFENG REN $^{3}$ and DEBAO WANG ${ }^{1}$ \\ Departments of ${ }^{1}$ Endocrinology and ${ }^{2}$ Laboratory, Laiwu City People's Hospital; \\ ${ }^{3}$ Department of Medicine, Laicheng District Fangxia Hospital, Laiwu, Shandong 271199, P.R. China
}

Received November 3, 2014; Accepted February 11, 2016

DOI: $10.3892 /$ etm.2016.3123

\begin{abstract}
The aim of the present study was to investigate the expression levels of transforming growth factor (TGF)- $\beta 1$ and microRNA (miRNA)-145 in patients with diabetic foot ulcers (DFUs). A total of 26 patients with DFUs requiring amputation were enrolled in the study between January 2013 and August 2014. In addition, 15 trauma patients undergoing amputation over the same time period were included as a control group. Samples were collected from the blood, the dorsalis pedis arteries and muscles of the amputated limbs. The expression levels of TGF- $\beta 1$ mRNA and miRNA-145 in these samples was detected using reverse transcription-quantitative polymerase chain reaction. The expression levels of TGF- $\beta 1$ protein were evaluated using western blot analysis. In comparison with the control, the protein and mRNA expression levels of TGF- $\beta 1$ in the DFU patients was significantly higher in the serum and the dorsalis pedis arteries, and significantly lower in the muscles with ulcers. In contrast, the expression levels of miRNA-145 was significantly lower in the blood and the dorsalis pedis arteries, and significantly higher in the muscles with ulcers in DFU patients compared with the control. The results of the present study suggested that there exists an inverse correlation between the expression levels of miRNA-145 and TGF- $\beta 1$ in patients with DFU; thus suggesting that miRNA-145 may regulate the expression of TGF- $\beta 1$ in patients with DFUs.
\end{abstract}

\section{Introduction}

Diabetes mellitus (DM) can cause serious health complications and lead to chronic damage and dysfunction of organs, including the eyes, kidneys, cardiovascular system and nervous system. Diabetic foot (DF) is one of the most serious

Correspondence to: Dr Debao Wang, Department of Endocrinology, Laiwu City People's Hospital, 1 Xuehu Street, Changshao Road, Laicheng, Laiwu, Shandong 271199, P.R. China E-mail: wdb333@126.com

Key words: microRNA-145, transforming growth factor- $\beta 1$, diabetic foot ulcers complications of DM. It is a major cause of morbidity and disability in patients with DM (1). Disorders associated with DF include ulceration, infection, vascular disease, Charcot arthropathy and neuropathic fracture. Slight foot injuries in patients with DM, particularly in elderly individuals with a long duration of DM, can develop into ulcers because of the high blood glucose levels at the wounds, and may ultimately lead to amputation.

DFU is characterized by chronic poor blood flow in the lower extremities (2). The study of vascular disease of the lower extremity is important in DFU research. In the course of DFU, vascular disease can lead to alterations in the expression levels of regulatory factors such as hypoxia-inducible factor-1 $\alpha$, vascular endothelial growth factor and transforming growth factor (TGF)- $\beta 1(3,4)$. TGF- $\beta 1$ is important in the morphological changes, proliferation, differentiation and healing of cells. Madhyastha et al (5) reported that TGF- $\beta 1$ induced the expression of miRNA-21 under high-glucose conditions, and this effect was dependent on $\mathrm{NF}-\kappa \mathrm{B}$ activation; therefore, it was suggested that manipulation of the TGF- $\beta 1 / \mathrm{NF}-\kappa \mathrm{B} / \mathrm{miRNA}-21$ pathway may serve as an innovative approach in the development of therapeutics to treat diabetic ulcers. Previous studies have investigated the regulation of the expression of genes associated with the TGF- $\beta 1$ pathway by miRNA-145 in gallbladder cancer (6), cardiac myofibroblast differentiation (7), lung fibrosis (8) and cystic fibrosis (9). However, to the best of our knowledge, there have been no previous reports on the correlation between the expression levels of miRNA-145 and TGF- $\beta 1$ in patients with DFUs.

In the present study, the expression levels of TGF- $\beta 1$ and miRNA-145 were detected in the serum, dorsalis pedis arteries and muscles of the amputated limbs of patients with DFUs, in order to investigate whether miRNA-145 regulates the expression of TGF- $\beta 1$ in DFU patients.

\section{Materials and methods}

Patients. A total of 26 patients with DFUs (16 males and 10 females; mean age, 61.6 \pm 5.1 years; age range, 53-68 years) with amputation, and 15 trauma patients ( 9 males and 6 females; mean age, 52.3 \pm 7.8 years; age range, $46-61$ years) undergoing amputation, at Laiwu City People's Hospital (Laiwu, China) were enrolled in the present study between January 2013 and August 2014. The present study was approved by the Ethics 
Committee of Laiwu City People's Hospital and prior written informed consent was obtained from all patients.

Peripheral blood samples were collected in the early morning from fasted patients prior to amputation. The serum was separated and stored at $-80^{\circ} \mathrm{C}$. The dorsalis pedis arteries and muscles with ulcers were collected from the amputated limbs of the patients shortly following amputation and stored in liquid nitrogen.

Reverse transcription-quantitative polymerase chain reaction (RT-qPCR) analysis. Total RNA was extracted from the samples of dorsalis pedis arteries and muscles using TRIzol reagent (Yisheng Biotechnology Co., Ltd., Shanghai, China) and the serum using an miRNeasy Serum/Plasma kit (Jianlun Biological Technology Co., Ltd., Guangzhou, China). Total RNA (4 $\mu \mathrm{l})$ was reverse transcribed to form cDNA using a TIANscript RT kit (Tiangen Biotech Co., Ltd., Beijing, China). RT-qPCR analysis of miRNA and mRNA levels was performed using the iQ5 Real-Time PCR detection system (Bio-Rad Technologies, Inc., Hercules, CA, USA) with miRcute miRNA qPCR detection and SuperReal PreMix (SYBR Green) kits (both from Tiangen Biotech Co., Ltd.). The $2^{-\Delta \Delta \mathrm{Cq}}$ method was used to calculate the expression levels of the TGF- $\beta 1$ gene and miRNA-145 relative to the endogenous control genes: $\beta$-actin and U6 small nuclear RNA (RNU6), respectively. PCR reactions were conducted using the CFX96 Touch $^{\mathrm{TM}}$ thermal cycler (Bio-Rad Technologies, Inc.), in which the following primers were used: TGF- $\beta 1$, 5'-GGACACCAACTATTGCTTCAG-3' and 5'-TCCAGACTCCAAATGTAG-3'; $\beta$-actin, 5'-TTCCAG CCTTCCTTCCTGG-3' and 5'-TTGCGCTCAGGAGGA GGAAT-3'; miRNA-145, 5'-ACACTCCAGCTGGGGTCC AGTTTTCCCAGGAA-3' and 5'-CTCAACTGGTGTCGT GGAGTCGGCAATTCAGTTGAG-3'; RNU6, 5'-ACACTC CAGCTGGGTTCGTGAAGCGTTCCA-3' and 5'-CTCAAC TGGTGTCGTGGAGTCGGCAATTCAGTTGAG-3' (Sangon Biotech Co.,Ltd., Shanghai, China). PCR procedures for TGF- $\beta 1$ and $\beta$-actin comprised template denaturation at $95^{\circ} \mathrm{C}$ for $2 \mathrm{~min}$, then 30 cycles of $94^{\circ} \mathrm{C}$ for $45 \mathrm{sec}, 55^{\circ} \mathrm{C}$ for $55 \mathrm{sec}$ and $72.0^{\circ} \mathrm{C}$ for $1 \mathrm{~min}$, and a final extension at $72^{\circ} \mathrm{C}$ for $10 \mathrm{~min}$. PCR procedures for miRNA-145 and RNU6 comprised template denaturation at $95^{\circ} \mathrm{C}$ for $30 \mathrm{sec}$, then 40 cycles of $95^{\circ} \mathrm{C}$ for $5 \mathrm{sec}, 55^{\circ} \mathrm{C}$ for $34 \mathrm{sec}$ and $72.0^{\circ} \mathrm{C}$ for $34 \mathrm{sec}$, and a final extension at $72^{\circ} \mathrm{C}$ for $10 \mathrm{~min}$.

Western blot analysis. Total proteins were harvested from the samples and the concentrations of the proteins were determined using a Bicinchoninic Acid Protein Assay kit (Real-Times Biotechnology Co., Ltd., Beijing, China). Then, $20 \mu \mathrm{g}$ total proteins were separated by $10 \%$ sodium dodecyl sulfate-polyacrylamide gel electrophoresis (Beyotime Institute of Biotechnology, Haimen, China), and then transferred to polyvinylidene difluoride membranes (Bio-Rad Laboratories, Inc.) for western blotting. After blocking with 5\% non-fat milk for $1 \mathrm{~h}$ at room temperature, the membranes were incubated at $4^{\circ} \mathrm{C}$ overnight with rabbit anti-human TGF- $\beta 1$ (1:500; cat. no. ab92486; Abcam, Cambridge, MA, USA) and rabbit anti-human $\beta$-actin (1:5,000; cat. no. ab8227; Abcam) polyclonal antibodies. After washing with phosphate-buffered saline three times, the membranes were incubated with horseradish peroxidase (HRP)-conjugated goat anti-rabbit $\operatorname{IgG}(1: 3,000$; cat. no. ab6721; Abcam) for $1 \mathrm{~h}$ at room temperature. Bound antibodies

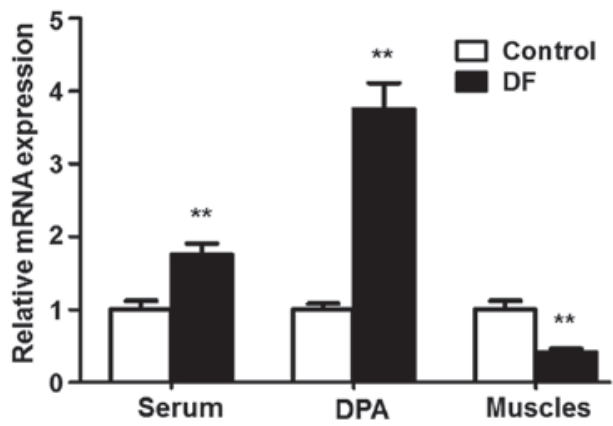

Figure 1. Expression of transforming growth factor (TGF)- $\beta 1 \mathrm{mRNA}$ in patients with diabetic foot (DF) ulcers. Reverse transcription-quantitative polymerase chain reaction was performed to evaluate the relative expression level of TGF- $\beta 1$ mRNA in the serum, and the dorsalis pedis arteries (DPAs) and muscles of amputated limbs in DF patients $(n=26)$ and control trauma patients $(n=15)$. Data are presented as means \pm standard deviation, and were analyzed by one-way analysis of variance. ${ }^{* *} \mathrm{P}<0.01$ vs. the control.

were detected using an enhanced chemiluminescence system (Abcam). The mean normalized optical density (OD) of the TGF- $\beta 1$ protein band relative to the OD of the $\beta$-actin band from the same individual was calculated using Image Lab software, version 3.0 (Bio-Rad Laboratories, Inc.).

Statistical analysis. All data were processed using SPSS software, version 18.0 (SPSS, Inc., Chicago, IL, USA). Data are presented as the mean \pm standard deviation. A normality test was performed on all data. One-way analysis of variance was conducted in order to determine the statistical significance of differences. $\mathrm{P}<0.05$ was considered to indicate a statistically significant difference.

\section{Results}

Patient characteristics. The lesions of peripheral arterial disease (PAD) in the DFU patients include arterial intimal thickening $(\geq 1 \mathrm{~mm})$, single or multiple artery plaques, artery stenosis and occlusion. PAD with one of these four types of lesions was designated as mild, with two as moderate and three or more as severe (10). In the present study, all $26 \mathrm{DFU}$ patients had previously been diagnosed with PAD, of which 1 patient had mild PAD, 6 patients had moderate PAD and 19 patients had severe PAD.

Expression of TGF- $\beta 1 \mathrm{mRNA}$ in DFU patients. To investigate the expression of TGF- $\beta 1$ in DFU patients, the levels of TGF- $\beta 1$ mRNA were detected using RT-qPCR analysis. The expression level of TGF- $\beta 1$ in the serum of DFU patients was significantly higher than that in the serum of the control trauma patients $(1.00 \pm 0.12$ vs. $1.75 \pm 0.16$, respectively; $\mathrm{P}<0.01$; Fig. 1). TGF- $\beta 1$ mRNA expression was also detected in the dorsalis pedis arteries of the amputated limbs. Consistent with the observations in the serum, the expression level of TGF- $\beta 1$ mRNA in the dorsalis pedis arteries of DFU patients was significantly higher than that in the corresponding arteries of the control $(1.00 \pm 0.08$ vs. $3.75 \pm 0.36$, respectively; $\mathrm{P}<0.01$, Fig. 1). Notably, the expression level of TGF- $\beta 1$ mRNA was significantly lower in the ulcerated muscles of the amputated limbs of DFU patients compared with those in the amputated 
A

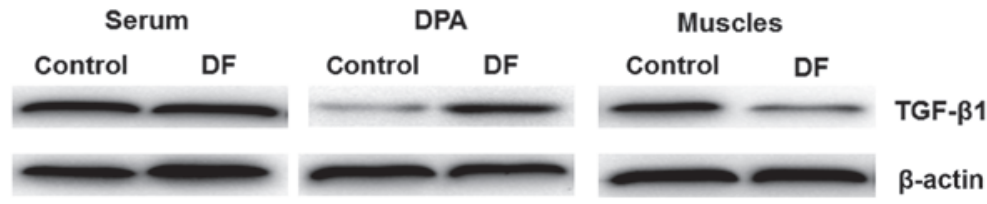

B

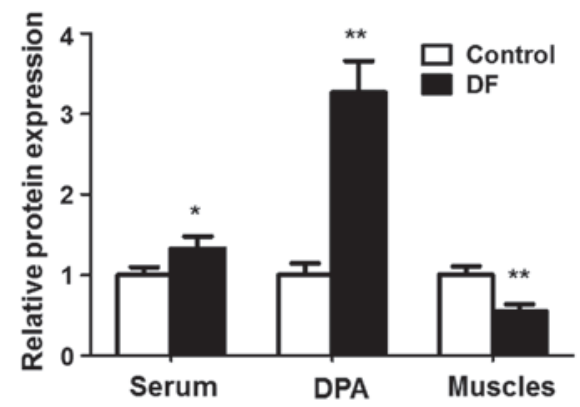

Figure 2. Expression of transforming growth factor (TGF)- $\beta 1$ protein in patients with diabetic foot (DF) ulcers. Western blot analysis was performed to evaluate the TGF- $\beta 1$ protein expression level in the serum, and the dorsalis pedis arteries (DPAs) and muscles of amputated limbs in DF patients (n=26) and control trauma patients $(\mathrm{n}=15)$. (A) Representative results and (B) quantitative comparison of the data obtained from the two groups. Data are presented as means \pm standard deviation, and were analyzed by one-way analysis of variance. ${ }^{*} \mathrm{P}<0.05$ and ${ }^{* *} \mathrm{P}<0.01$ vs. the control.

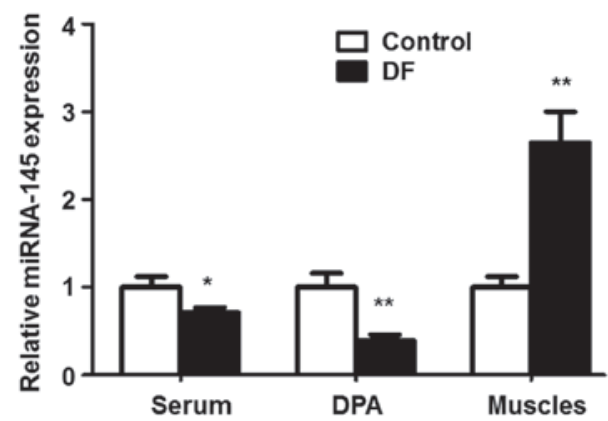

Figure 3. Expression of microRNA (miRNA)-145 in patients with diabetic foot (DF) ulcers. Reverse transcription-quantitative polymerase chain reaction was performed to evaluate the relative expression level of miRNA-145 in the serum, and the dorsalis pedis arteries (DPAs) and muscles of amputated limbs in DF patients $(n=26)$ and control trauma patients $(n=15)$. Data are represented as means \pm standard deviation, and were analyzed by one-way analysis of variance. ${ }^{*} \mathrm{P}<0.05$ and ${ }^{* *} \mathrm{P}<0.01$ vs. the control.

leg muscles of the control patients $(1.00 \pm 0.12$ vs. $0.41 \pm 0.05$, respectively; $\mathrm{P}<0.01$; Fig. 1). These results reveal a distinct expression pattern of TGF- $\beta 1$ mRNA in DFU patients.

Expression of TGF- $\beta 1$ protein in DFU patients. To confirm the results of the TGF- $\beta 1$ mRNA expression analysis described above, the levels of TGF- $\beta 1$ protein were detected using western blot analysis. As shown in Fig. 2, compared with the control, the expression of TGF- $\beta 1$ protein in DFU patients was significantly higher in the serum $(1.00 \pm 0.10$ vs. $1.33 \pm 0.15$, respectively; $\mathrm{P}<0.05)$ and the dorsalis pedis arteries $(1.00 \pm 0.15$ vs. $3.27 \pm 0.39$, respectively; $\mathrm{P}<0.01)$, but significantly lower in the ulcerated muscles of the amputated limb $(1.00 \pm 0.11 \mathrm{vs}$. $0.55 \pm 0.09$, respectively; $\mathrm{P}<0.01)$. These results indicate that the expression level of TGF- $\beta 1$ protein correlates well with the TGF- $\beta 1$ mRNA expression level, and further confirms the expression pattern of TGF- $\beta 1$ in DFU patients.

Expression of miRNA-145 in DFU patients. In order to investigate whether the expression of TGF- $\beta 1$ is negatively regulated by miRNA-145 in patients with DFUs, miRNA-145 expression levels were evaluated using RT-qPCR analysis. As shown in Fig. 3, compared with the control, in the DFU patients the expression of miRNA-145 was significantly lower in the serum $(1.00 \pm 0.12$ vs. $0.71 \pm 0.06$, respectively; $\mathrm{P}<0.05)$ and the dorsalis pedis arteries $(1.00 \pm 0.16$ vs. $0.39 \pm 0.07$, respectively; $\mathrm{P}<0.01)$, but significantly higher in the ulcerated muscles $(1.00 \pm 0.12$ vs. $2.65 \pm 0.35$, respectively; $\mathrm{P}<0.01)$. These results indicate that an inverse correlation exists between miRNA-145 and TGF- $\beta 1$ expression levels in patients with DFUs.

\section{Discussion}

In the present study, the expression levels of TGF- $\beta 1$ and miRNA-145 were investigated in patients with DFUs and control trauma patients undergoing amputation. The results unveiled a distinct expression pattern of TGF- $\beta 1$ in the DFU patients. An inverse correlation of the expression of miR-145 with the expression of TGF- $\beta 1$ was also observed in the patients with DFUs.

Peripheral artery disease (PAD) is an important factor leading to DFU. Hao et al reported that DFUs are more evident in patients with PAD, which is further reflected by a significantly greater number of underlying cases of infection and disabling comorbidity (11). PAD was evident in all 26 patients with DFUs enrolled in the present study. Janda et al observed a significant correlation of increased TGF- $\beta 1$ expression levels with atherosclerotic changes in the carotid arteries of patients requiring peritoneal dialysis (12). In the present study, it was found that the levels of TGF- $\beta 1$ expression in the serum and dorsalis pedis arteries of the amputated limbs of DFU patients were significantly higher than those in the control patients. The results also suggest that a correlation exists between increased TGF- $\beta 1$ expression and vascular diseases in DFU patients.

It has been reported that TGF- $\beta 1$ can stimulate the secretion of extracellular matrix (ECM) and plays important roles in the morphological changes, proliferation and differentiation of mononuclear cells, brain cells and osteocytes (13-15). 
In vivo studies have suggested that the upregulation of TGF- $\beta 1$ can promote wound healing and the formation of typical granulation tissues $(16,17)$. In the present study, TGF- $\beta 1$ expression levels were observed to be significantly decreased in the ulcerated muscles of the amputated limbs of DFU patients. This may be one of the factors affecting the healing of DFUs.

TGF- $\beta 1$ expression can be regulated by, for example, nemo-like kinase and Smad $(18,19)$. It has been reported that TGF- $\beta 1$ may also be post-transcriptionally regulated by miRNA (20). The present study provides direct evidence of the inverse correlation of the expression of miRNA-145 and TGF- $\beta 1$ in DFU patients, which is consistent with the aforementioned studies. These results suggest that miRNA-145 regulates the expression of TGF- $\beta 1$ in DFU patients.

DF is the most common cause of hospitalization of diabetic patients. The incidence of DF is particularly high in the elderly populations of developing countries. Every year, 4 million diabetic patients develop DFUs. Worldwide, one person undergoes DF amputation every $30 \mathrm{sec}$ (21). However, $85 \%$ of these amputations could be avoided (21), and it is important to identify reliable and stable molecular markers of DFU in diabetic patients. In the present study, it was found that the expression of miRNA-145 is negatively correlated with TGF- $\beta 1$ expression. Since TGF- $\beta 1$ plays important roles in DFU development (5), miRNA-145 might be a potential marker or therapeutic target for the diagnosis or treatment of DFU. The effects of miRNA-145 on DFUs and the underlying mechanisms merit further investigation.

\section{Acknowledgements}

The authors of the present study would like to thank Dr Fenglian Liu, director of Laiwu City People's Hospital, for help in the choice of the research topic, the design and guidance of the experiments, analysis of the data and the writing and revision of this manuscript.

\section{References}

1. Rdeini WM, Agbenorku P and Mitish VA: Strategy of surgical management of peripheral neuropathy form of diabetic foot syndrome in Ghana. Plast Surg Int 2014: 185023, 2014.

2. Cakmak T, Metin S, Yaman H, Demirbas S, Yildiz S, Turker T and Akin A: The effect of hyperbaric oxygen therapy on ischemia-modified albumin levels in people with diabetes with foot ulcers. Undersea Hyperb Med 41: 277-281, 2014.

3. Zhang J, Guan M, Xie C, Luo X, Zhang Q and Xue Y: Increased growth factors play a role in wound healing promoted by noninvasive oxygen-ozone therapy in diabetic patients with foot ulcers. Oxid Med Cell Longev 2014: 273475, 2014.

4. Thangarajah H, Vial IN, Grogan RH, Yao D, Shi Y, Januszyk M, Galiano RD, Chang EI, Galvez MG, Glotzbach JP, et al: HIF-1alpha dysfunction in diabetes. Cell Cycle 9: 75-79, 2010.
5. Madhyastha R, Madhyastha H, Pengjam Y, Nakajima Y, Omura S and Maruyama M: NFkappaB activation is essential for miR-21 induction by TGF $\beta 1$ in high glucose conditions. Biochem Biophys Res Commun 451: 615-621, 2014.

6. Letelier P, García P, Leal P, Álvarez H, Ili C, López J, Castillo J, Brebi P and Roa JC: miR-1 and miR-145 act as tumor suppressor microRNAs in gallbladder cancer. Int J Clin Exp Pathol 7: 1849-1867, 2014

7. Wang YS, Li SH, Guo J, Mihic A, Wu J, Sun L, Davis K, Weisel RD and Li RK: Role of miR-145 in cardiac myofibroblast differentiation. J Mol Cell Cardiol 66: 94-105, 2014.

8. Yang S, Cui H, Xie N, Icyuz M, Banerjee S, Antony VB, Abraham E, Thannickal VJ and Liu G: miR-145 regulates myofibroblast differentiation and lung fibrosis. FASEB J 27: 2382-2391, 2013.

9. Megiorni F, Cialfi S, Cimino G, De Biase RV, Dominici C, Quattrucci S and Pizzuti A: Elevated levels of miR-145 correlate with SMAD3 down-regulation in cystic fibrosis patients. J Cyst Fibros 12: 797-802, 2013.

10. Liu WF, Wu WQ, Chen LQ, Yang WP and Wen H: Analysis of the incidence of diabetic lower extremities vascular disease, pathological changes and the related factors. J Pract Med 26: 2323-2325, 2010.

11. Hao D, Hu C, Zhang T, Feng G, Chai J and Li T: Contribution of infection and peripheral artery disease to severity of diabetic foot ulcers in Chinese patients. Int J Clin Pract 68: 1161-1164, 2014.

12. Janda K, Krzanowski M, Dumnicka P, Kuśnierz-Cabala B, Kraśniak A and Sułowicz W: Transforming growth factor beta 1 as a risk factor for cardiovascular diseases in end-stage renal disease patients treated with peritoneal dialysis. Clin Lab 60: 1163-1168, 2014.

13. Cicha I, Yilmaz A, Klein M, Raithel D, Brigstock DR, Daniel WG, Goppelt-Struebe $\mathrm{M}$ and Garlichs CD: Connective tissue growth factor is overexpressed in complicated atherosclerotic plaques and induces mononuclear cell chemotaxis in vitro. Arterioscler Thromb Vasc Biol 25: 1008-1013, 2005.

14. Zeng L, He X, Wang Y, Tang Y, Zheng C, Cai H, Liu J, Wang Y, $\mathrm{Fu}$ Y and Yang GY: MicroRNA-210 overexpression induces angiogenesis and neurogenesis in the normal adult mouse brain. Gene Ther 21: 37-43, 2014.

15. Kanaan RA, Aldwaik M and Al-Hanbali OA: The role of connective tissue growth factor in skeletal growth and development. Med Sci Monit 12: RA277-RA281, 2006.

16. Hameedaldeen A, Liu J, Batres A, Graves GS and Graves DT: FOXO1, TGF- $\beta$ regulation and wound healing. Int J Mol Sci 15: $16257-16269,2014$

17. Okizaki S, Ito Y, Hosono K, Oba K, Ohkubo H, Amano H, Shichiri M and Majima M5: Suppressed recruitment of alternatively activated macrophages reduces TGF- $\beta 1$ and impairs wound healing in streptozotocin-induced diabetic mice. Biomed Pharmacother 70: 317-325, 2015.

18. Xiao Z, Zhang J, Peng X, Dong Y, Jia L, Li H and Du J: The Notch $\gamma$-secretase inhibitor ameliorates kidney fibrosis via inhibition of TGF- $\beta / \mathrm{Smad} 2 / 3$ signaling pathway activation. Int J Biochem Cell Biol 55: 65-71, 2014.

19. Shi Y, Ye K, Wu H, Sun Y, Shi H and Huo K: Human SMAD4 is phosphorylated at Thr9 and Ser138 by interacting with NLK. Mol Cell Biochem 333: 293-298, 2010.

20. Martin J, Jenkins RH, Bennagi R, Krupa A, Phillips AO, Bowen $\mathrm{T}$ and Fraser DJ: Post-transcriptional regulation of transforming growth factor beta-1 by microRNA-744. PLoS One 6: e25044, 2011.

21. Barshes NR, Gold B, Garcia A, Bechara CF, Pisimisis G and Kougias P: Minor amputation and palliative wound care as a strategy to avoid major amputation in patients with foot infections and severe peripheral arterial disease. Int J Low Extrem Wounds 13: 211-219, 2014. 